\title{
Já é alvorada, irmã da manhã: o canto de esperança do sambista
}

\author{
Already dawn, sister of the morning: the song of hope of the samba \\ Guilherme Primo de Mendonça* \\ Universidade Tecnológica Federal do Paraná \\ Curitiba, Paraná, Brasil \\ Marilu Martens Oliveira** \\ Universidade Tecnológica Federal do Paraná \\ Curitiba, Paraná, Brasil \\ Maurício Cesar Menon ${ }^{* * *}$ \\ Universidade Tecnológica Federal do Paraná \\ Curitiba, Paraná, Brasil \\ Evandro de Melo Catelão**** \\ Universidade Tecnológica Federal do Paraná \\ Curitiba, Paraná, Brasil
}

\begin{abstract}
Resumo: Neste artigo, estudamos os termos como aurora e alvorada ${ }^{1}$ inscritos em letras de samba, uma vez que entendemos que representam o canto de esperança do cantautor do morro. A fim de analisarmos as letras sob as perspectivas do real e não real, apoiamo-nos nas pesquisas de Coelho (1984), Bachelard (1988; 2008), Chevalier e Gheerbrant (1988), Bloch (2005), Romanelli (2015), Chauí (2016), Mattuella (2016) e Viera (2017). Fazem parte da análise, ainda, os processos de construção do cenário onde habitam os compositores das canções, assim como os de romantização do samba. Lançamos mão, pois, da obra de Vianna (1995), quando traz à tona o mistério do samba; Dantas (1988), que postula as relações entre o estético e o social; Benchimol (1992), por descrever a formação e proliferação dos subúrbios e Galvão (2017), posto que discute a idealização do suburbano. O samba nos possibilita compreender os desejos que cercam o sujeito do morro e de saltarmos junto dele para o que ainda não emergiu, mas que já foi idealizado.
\end{abstract}

Palavras-chave: Esperança. Samba. Suburbano. Utopia.

\footnotetext{
* Mestrando em Ensino de Ciência Humanas, Sociais e da Natureza pela Universidade Tecnológica Federal do Paraná; graduado em Letras - Vernáculas pela Universidade Estadual de Londrina. E-mail: guiprimo@hotmail.com.

** Doutora em Letras pela Universidade Estadual Paulista Júlio de Mesquita Filho. Professora Titular da Universidade Tecnológica Federal do Paraná.E-mail: yumartens@hotmail.com.

*** Doutor em Letras pela Universidade Estadual de Londrina. Professor da Universidade Tecnológica Federal do Paraná. E-mail: mcmenon@utfpr.edu.br.

**** Doutor em Letras pela Universidade Federal do Paraná. Professor Adjunto da Universidade Tecnológica Federal do Paraná. E-mail: evandrocatelao@gmail.com.

${ }_{1}^{1}$ Ainda que pudéssemos trazer à tona definições mais específicas para os termos em destaque, optamos por seguir no trilho poético, acompanhando as letras das canções. Assim, refletimos sobre aurora e alvorada pela seguinte proposição: “[...] se a luz solar morre toda noite, também é verdade que ela renasce toda manhã, e o homem, assemelhando seu destino ao da luz, obtém dela esperança e confiança na perenidade da vida e de sua força." (CHEVALIER; GHEERBRANT, 1988, p. 569).
} 


\begin{abstract}
In this article, we study the terms like dawn and alvorada included in samba lyrics, once we understand that represent the hope in the sings of the songwriter's of the hill. In order to analyze the letters under the perspectives of real and not real, we support in Coelho (1984), Bachelard (1988; 2008), Chevalier and Gheerbrant (1988), Bloch (2005), Romanelli (2015), Chauí (2016), Mattuella (2016) and Viera (2017). Make part of the analysis, the construction processes of scenario where living the composers of the songs, as well as the romantization of samba. We launched hand, thus, of the work of Vianna (1995), when he brings out the mystery of samba; Dantas (1988), which posits relations between aesthetic and social; Benchimol (1992), for describe the formation and proliferation of the suburbs and Galvão (2017), once that she discusses the creation of the marginalized. The samba enables us to understand the desires that surround the person of the hill and we jump with her for the that have not yet emerged, but that has already been idealized.
\end{abstract}

Keywords: Hope. Samba. Suburban. Utopia.

A perfeição seguirá sendo o privilégio tedioso dos deuses, mas neste mundo, neste mundo avacalhado e maldito, cada noite será vivida como se fosse a última e cada dia como se fosse o primeiro. (GALEANO, 2016, p. 9).

\title{
INTRODUÇÃO
}

Nos campos de uma natureza em constante transformação como a humana, os escritos artísticos nos ajudam a refletir sobre aquilo que é real. O resultado dessas considerações são obras que buscam, pela ótica do artista, o registro do presente, concomitantemente projetando, no espaço adiante/futuro, quadros deturpados daquele tempo. Daí o movimento de busca dos que as experimentam, visto que é comum visarem às novas possibilidades, pelo enfrentamento e pelas reconfigurações daquilo que em determinado tempo vivenciaram.

Cantar e contar o que não ocorreu, bem como aquilo a que almejam, faz dos sujeitos marginalizados difusores de suas perspectivas a respeito da vida em detrimento de uma realização comum, no viés colonialista, elaborada e praticada pela camada dominante. As canções populares, mais especificamente o samba, oferecem-nos a possibilidade de compreendermos os desejos que cercam o bon vivant do morro e de saltarmos junto dele para o que ainda não se apresentou, mas que já foi desenhado.

Por exatamente abarcarem diferentes realidades, as letras das canções do gênero musical samba nos levam a analisar o modo como os compositores delas dialogam com os seus interlocutores e indicam um provável futuro. Objetivamos estudar, por uma pesquisa analítica-documental, de cunho descritiva (TRIVIÑOS, 1987), os termos como aurora e alvorad ${ }^{2}$, como representando o canto de esperança do sambista. Para tanto, apoiamo-nos em estudos realizados por Coelho (1984), Bachelard (1988; 2008), Chevalier e Gheerbrant (1988), Bloch (2005), Romanelli (2015), Chauí (2016), Mattuella (2016) e Viera (2017) com o propósito de analisarmos as letras sob as perspectivas do real e do não real.

\footnotetext{
2 Ainda que pudéssemos trazer à tona definições mais específicas para os termos em destaque, optamos por seguir no trilho poético, acompanhando as letras das canções. Assim, refletimos sobre aurora e alvorada pela seguinte proposição: “[...] se a luz solar morre toda noite, também é verdade que ela renasce toda manhã, e o homem, assemelhando seu destino ao da luz, obtém dela esperança e confiança na perenidade da vida e de sua força." (CHEVALIER; GHEERBRANT, 1988, p. 569).
} 
De modo que não visualizamos o referencial teórico referente aos conceitos ligados à utopia, esperança e ao devaneio como suficiente para realizarmos nossa pesquisa, outros autores emergem na discussão. Passamos a incluir na análise os processos de construção dos subúrbios - cenário onde se inscrevem os compositores das canções —, assim como os de romantização do samba. Lançamos mão, pois, da obra de Vianna (1995), quando traz à tona o mistério do samba; Dantas (1988), que postula as relações entre o estético e o social; Benchimol (1992), por descrever a formação e proliferação dos subúrbios e Galvão (2017), que discute a idealização do suburbano.

\section{OS LUGARES DA UTOPIA}

Em meio aos estudos referentes à utopia, as proposições de Chauí (2016) são aqui elucidadas e servem como referencial devido ao fato de a autora abordar o diálogo entre o presente e futuro. Entretanto, nessa situação, prevalece o quadro do horizonte à frente e não o do contexto situado. Em outras palavras, a busca no futuro acontece de modo a descaracterizar o instantâneo e, portanto, fazer desse um lugar não ideal para aquilo que determinado sujeito está disposto a realizar.

A visualização e a certeza cantada nas canções populares, como exemplificamos com as letras de sambas analisadas abaixo, são sustentadas a partir de uma compreensão de utopia que emerge com a chegada do século XIX. No contexto dos sujeitos suburbanos, o reconhecimento da herança afro-brasileira pelos que compõem a elite governante das futuras metrópoles, possivelmente contribui para que aqueles aguardem a chegada de outras transformações. Contudo, a elevação do gênero musical samba a símbolo nacional se dá pelos projetos políticos.

Vislumbrados com os contextos já alterados, ainda que erroneamente, a parcela social destituída dos poderes que ditam o funcionamento urbano enquadra-se numa utopia que é "deduzida de teorias sociais e científicas, sua chegada é tida como inevitável porque a mancha da história e o conhecimento de suas leis universais garantem que ela se realizará." (CHAUÍ, 2016, p. 41). Apontamos que tal consciência frente ao futuro não inscreve aquela nesse prisma, dado que a poesia dos compositores versa sobre uma certeza — o dia que virá —, porém que não assegura a felicidade, os novos amores.

Em outras palavras, o socialismo utópico ergue-se contra o sofrimento dos humilhados e oprimidos, mas o socialismo científico é o conhecimento das causas materiais (econômicas e sociais) da humilhação e da opressão, ou seja, o modo de produção capitalista, fundado na luta de classes, que é determinada pela propriedade privada dos meios sociais de produção - a revolução socialista será, por isso mesmo, a passagem à propriedade social dos meios sociais de produção, passagem que será a ação política da classe economicamente explorada quando, por sua organização, conhecer-se a si mesma como classe. (CHAUí, 2016, p. 42).

\section{ESPERANÇA}

Num diálogo com a obra de Chauí (2016), o conceito de esperança aqui adotado nos distancia daquele pertencente a uma perspectiva idealista, a qual nos leva a pensar no 
futuro, desconsiderando o que já vivemos. Assim sendo, os interesses das "vítimas", os seus desejos, ajustam-se ao viés que é o da esperança concreta. Tais vítimas são os sujeitos que passaram por movimentos de exclusão dos direitos de deleitarem o essencial a elas. No caso dos que percorrem, desde os primórdios, remetendo às rodas de samba, poderíamos citar: o saneamento básico, a moradia decente, o reconhecimento identitário, a não-violência física e verbal.

De acordo com Bloch (2005), a esperança concreta se realiza frente à situação de insatisfação vivida por essas pessoas e que, em vista disso, delineiam novas fronteiras a serem ultrapassadas. O compositor das letras de canções populares, como um dos exemplos pertencentes à parcela destituída, encontra-se sob uma base real e canta as mudanças necessárias a serem realizadas. Por sua vez, o público, que visualiza nas letras uma situação distanciada da qual vive, também poderia ser inserido no conjunto dos que propagam as desejáveis modificações.

A base real da qual fala o autor é a relevância que o passado tem sobre o que é almejado pelos sujeitos e, portanto, como acima exposto, organizam-se de maneira coletiva na busca. A concretude, e não apenas o caráter tentado do que esperam, ocorre baseada na ideia de que o outro dia chegará, não sendo, desse modo, um pensamento abstrato. Nesse sentido, considerarmos canções que revelam as expectativas de uma porção de pessoas, por meio de termos que nos remetem ao certo, revela que lidamos com poesias que dizem respeito às utopias possíveis.

Compartilhando de um posicionamento marxista, apresentarmos o conceito de esperança sob os estudos de Bloch faz com que reflitamos, ainda que não seja nosso objetivo principal, sobre a força da ode como uma das formas de humanizarmos a sociedade. Essa da qual falamos é a que trabalha ao longo do dia, frequenta os espaços em que se canta o samba e, ao longo da madrugada, espera pelo novo que traz os caminhos sem pedras, fruto da esperança concreta. Em síntese, portanto, a esperança da qual falamos

[...] encontra-se no limiar da insatisfação do homem perante a sua condição histórico-social. É assim, por exemplo, que se pode afirmar, após analisar os limites humanos, que é muito bom o homem ser imperfeito, diferenciar-se dos animais por não ser acabado, pois só assim pode fazer algo. (VIEIRA, 2007, p. 6).

\section{ASPECTOS DAS LEITURAS}

Ao elevarmos a canção popular ao patamar da poesia, observaremos em seus versos pensamentos que confundem os que as admiram. Essa confusão decorre do fato de que ambas as formas artísticas propõem "uma reflexão sobre a vida", como aponta Dantas (1988, p. 28). Tal mensagem a ser transmitida é neste estudo representada por dois verbos que são sinônimos de refletir. Em outras palavras, refletir se transforma em revelar quando os compositores das canções abordam o presente e o passado, como também se converte em devaneio ao cuidarem do futuro. 
Uma vez que nossa proposta se inscreve nos aspectos relacionados aos devaneios dos sujeitos retratados na canção marginal ${ }^{3}$, consideramos a possibilidade de encarar o passado e o presente secundariamente; como a apoiar as expectativas, o futuro. Nossa pesquisa, reduzida a algumas letras de samba, projeta um olhar que, no campo de outros gêneros musicais, inclusive, ampliaria a gama de canções em que são idealizadas as expectativas de seus autores, a partir de termos próximos aos aqui considerados.

\title{
3.1 EXPECTATIVAS E ESPERANÇA NAS LETRAS DE SAMBAS
}

Detendo-nos nos primeiros versos da letra de Alvorada, composta por Angenor Oliveira, Carlos Moreira de Castro e Hermínio Bello de Carvalho ${ }^{4}$ observamos que o termo alvorada, repetido inúmeras vezes na obra, aproxima-se do verbo oriundo do substantivo utilizado no título da canção. Na primeira estrofe, é narrado o cenário da chegada do crepúsculo matutino ${ }^{5}$, o qual acarreta a vivacidade passada dos sujeitos para a natureza e vice-versa. Essa vivacidade da qual falamos se une aos diversos aspectos que, popularmente, levam-nos a perceber um semblante contrário ao da infelicidade.

\author{
Alvorada \\ Alvorada lá no morro \\ Que beleza \\ Ninguém chora \\ Não há tristeza \\ Ninguém sente dissabor \\ O sol colorindo é tão lindo \\ É tão lindo \\ E a natureza sorrindo \\ Tingindo, tingindo \\ A alvorada \\ Você também me lembra a alvorada \\ Quando chega iluminando \\ Meus caminhos tão sem vida \\ E o que me resta é bem pouco \\ Ou quase nada, do que ir assim, vagando \\ Numa estrada perdida \\ (CARTOLA; CACHAÇA; CARVALHO, 2017).
}

\footnotetext{
${ }^{3}$ A qualidade marginal que afirmarmos carregar o samba acompanha as mudanças no cenário urbano do Rio de Janeiro do início do século XX. "Até Pereira Passos, o Centro do Rio de Janeiro misturava de tudo [...]. A partir principalmente da abertura da Avenida Central, hoje Rio Branco, com a destruição dos cortiços, [...] Os pobres foram expulsos para novos bairros da Zona Norte ou para favelas espalhadas por toda a cidade." (VIANNA, 1995, p. 21-22).

${ }^{4}$ Os dois primeiros, respectivamente famosos pelos apelidos de Cartola e de Carlos Cachaça.

${ }^{5}$ Embora comumente encontremos o termo crepúsculo relacionado ao pôr do sol, em Buarque (1993, p.

23) "Crepúsculo matutino" seria uma das definições para alvorada.
} 
Embora não tomemos como objetivo tratar de um dos resultados da urbanização das grandes metrópoles, que é a habitação do morro ${ }^{6}$ (favelas, hoje denominadas comunidades), pontuamos, ainda que rapidamente, o que parte dos suburbanos visualiza antes do amanhecer. Numa perspectiva que julga o crescimento das cidades e, por conseguinte, a falta de amparo aos que compõem a minoria destituída, destacamos um dos, entre os vários, problemas críticos enfrentados por eles desde o século XIX.

A crise sanitária refletia a violenta deterioração das condições de vida da população trabalhadora do Rio de Janeiro, população flutuante e miserável, continuamente engrossada por novas levas de imigrantes. Foi o produto do aguçamento das contradições inerentes à transição para o capitalismo, à crescente acumulação e concentração do capital e da força de trabalho no espaço urbano carioca. (BENCHIMOL, 1992, p. 178).

Quanto à presença dos sentimentos de comunidade presentes nas práticas dos admiradores e dos compositores do gênero musical samba, como observamos na primeira estrofe, na qual "Ninguém" se encontra entristecido, deve-se ao fato de que ambos

Aspiravam à afirmação de uma identidade, ao mesmo tempo que se erigiam em focos de resistência à opressão e à descaracterização. Desse modo, procuravam alicerçar a auto-estima (sic) e proteger-se do racismo. A partir de então assistimos a seus esforços para adquirir legitimidade, sobretudo quanto ao desempenho nas ruas da cidade. Devotaram-se a obter o direito de escapar ao gueto e realizar suas festividades extramuros. (GALVÃO, 2017).

O canto de esperança, como retrata Galvão, ainda poderia ser associado a uma visão do morro próxima à do asfalto; isto é, num olhar distanciado do chão dos subúrbios, onde as marcas das diferentes violências brilham. Reluzem munições de armas de fogo, reluz a água suja que percorre a superfície — sinal da falta de saneamento. Em Eu sou favela ${ }^{7}$, Bezerra da Silva amplifica a voz dos que se orgulham de povoarem as íngremes ladeiras, depósito dos mais diversos projetos sociais e, ao mesmo tempo, excluído da proposta de sociedade.

Mais popular entre a high society, o samba pouco conduz o povo a enxergá-lo enquanto arte panfletária, diferentemente do rap. A idealização, a romantização da pobreza, por conseguinte os contextos que a cercam, são visualizadas em outras canções que, somadas às aqui analisadas, nos remetem ao período artístico de valorização da natureza. Canções como Chão de estrelas e Ave Maria do morro acentuam tal caráter nãopanfletário, projetando a favela como ambiente digno de moradia ${ }^{8}$.

Tais considerações nos levam ao estudo de outras letras, que complementam tal caráter acima exposto:

\footnotetext{
${ }^{6}$ No tal morro, mesmo que não haja a "vestimenta", que a presença dos problemas seja quase que em mesmo número dos habitantes que nele vivem, canta Silvio Caldas que "É sempre feriado nacional" (ORESTES; CALDAS, 2017).

${ }^{7}$ Composição de Sérgio Mosca e Noca da Portela.

${ }^{8}$ Conforme atesta Bentes (2007, p. 247), "A miséria desaparece sob a capa de uma segunda natureza e de uma pobreza não-problemática.".
} 


\begin{abstract}
Músicas como "Cordão", "Samba de Orly", "Acorda Amor", "Viola Enluarada", "Aroeira", "Louvação", "Ponteio", "Disparada", "A Estrada e o Violeiro" e "Apesar de Você" fazem parte de uma proposta renovadora, desnudando a realidade [...]. O triste cotidiano é revelado, surgindo as canções que, embora denunciem e protestem, são chamadas por Walnice Galvão em seu ensaio "MMPB" - uma análise ideológica" de escapistas. Ela mostra que a História não é assumida, que há uma evasão à responsabilidade pessoal (tanto do cantor-autor como dos ouvintes), e que a desculpa é o "dia que virá" e o "mito da canção que consola" (canto para anunciar "o dia que virá", canto "para me consolar"). Todos se eximem da responsabilidade social, não se colocando como sujeitos da História [...]. (OLIVEIRA, 1996, p. 1-2).
\end{abstract}

Num segundo momento da composição, é explícita a isomorfia que os autores lançam mão para cantarem a chegada de uma pessoa, que não é definida por adjetivo ou substantivo, mas pelo pronome de tratamento "Você", ao raiar do dia. Diferentemente do apontado na primeira estrofe, momento em que são citados os que habitam no morro, o eu-lírico se transforma conforme o despontar do dia. Sublinhamos que, ao utilizar o verbo iluminar no gerúndio, o advento da pessoa não muda os "caminhos" repentinamente, mas os altera, como figuramos, vagarosamente.

A leitura da composição nos remete, pois, à ideia de que na primeira parte temos uma situação descritiva, enquanto que na segunda, um monólogo dialógico. No trecho em que há a interpelação do "Você", fica-nos clara a imagem de um final desesperançoso, apesar do surgimento dela. Ou seja, ao posicionarmos lado a lado a pessoa que se faz presente e a alvorada, observaremos que, embora o autor as coloque como iluminadoras dos trilhos pelos quais percorrem os habitantes do morro, e ele, também, é a natureza quem prevalece?

Distante de um olhar utópico frente aos novos rumos a serem percorridos pelo sujeito descrito na canção, o futuro que desenham os letristas não parece ser algo suposto. Sustentamos essa posição, de maneira que não é abordado direta nem indiretamente o desejar, mas o que se assemelha a uma afirmativa, a um apontamento. A certeza relatada, seja na primeira estrofe, seja na segunda, leva-nos a interpretar que, independentemente do que é verificado naquele contexto exposto, o morro e a alvorada o modificam e se colocam a alegrá-lo.

Noutro estudo a respeito da obra em análise, a perspectiva empregada em um patamar distinto do qual Benchimol (1992) postula

É a [da] antevisão, [que] só possível nos entremeios do mundo real com o dos sonhos, do "novo dia", que bem poderia ser hoje, finalmente instaurado. Alheia ao cotidiano da realidade, a beleza se constitui e se faz presente naquele instante mágico, construindo a paisagem do morro na aurora. (ROMANELLI, 2015, p. 115 acréscimos nossos).

É nos apoiando na ideia de que "Pensar significa transpor. Contudo, de tal maneira que aquilo que está aí não seja ocultado nem omitido.” (BLOCH, 2005, p.14), que discutiremos Aurora de paz. A canção é fruto da parceria entre Antônio Carlos Ferreira de

${ }^{9}$ Isto é, quem verdadeiramente altera o contexto é a luz que irradia no horizonte. 


\title{
das Letras
}

Brito, no mundo do samba conhecido por Cacaso, e Elton Antônio de Medeiros, cujo nome artístico é Elton Medeiros.

\author{
Aurora de paz. \\ Olha pra frente \\ E sente essa aurora \\ Que vai nascer \\ Segue adiante \\ Pois em cada instante \\ Você vai ver \\ Que o amor que a gente perde \\ Nasceu para se perder \\ E se o amor da gente morre \\ A gente não vai morrer \\ Se não ficou era ilusão \\ Não seja assim tão infeliz \\ Que ainda existe um coração \\ Que vai abrigar outro amor \\ Diferente da ilusão \\ Enfrente a vida sorrindo \\ Nossa manhã já vem vindo \\ Repare que dia lindo \\ Pra the consolar \\ Prepare o seu coração \\ Que essa aurora é de paz \\ E quem já sofreu uma vez \\ Desta vez não sofre mais \\ (Pra nunca mais) \\ (CACASO; MEDEIROS, 2017).
}

A citação que nos remete ao pensador Ernst Bloch retrata, por meio de laços estreitos, aquilo que é colocado pelos compositores do samba em análise. Em determinado trecho da obra, o autor aponta que a

[...] transposição tem relação com essa capacidade humana de deixar-se afetar pelo existente em movimento, pela sensibilidade de saber o presente como não suficiente, de esperar o diferente e, mais ainda, de ocupar-se na construção de um futuro que não seja um vazio. (MATTUELLA, 2016, p. 157, destaques do autor).

Sob o ângulo da transposição, portanto, poderíamos afirmar que o elemento que a ocasiona, no samba Aurora de paz, é o início do dia. De outra maneira, no entanto, destacamos que, semelhante ao que ocorre na letra de Alvorada, a aurora ilumina os caminhos do eu-lírico, tornando-o capaz de ensinar ao seu interlocutor, representado pelo pronome de tratamento "Você", alguns fatos decorrentes do ato de amar. Assim, aquele se apoia no anterior, no que esteve em movimento e numa tentativa, ao que nos parece, de preparar o sujeito com o qual trava o diálogo para os momentos futuros.

Ainda que os compositores da canção afirmem veementemente os acontecimentos a serem aguardados pelo outro, entendemos que o discurso deles se encontra no campo da 
utopia. Atestamos tal fato, já que o retrato de um provável futuro, o acontecimento do verdadeiro amor, depende não apenas da aurora, mas de alguém disposto a amar. O oposto dessa utopia é observado em Alvorada, pois o sorriso das pessoas e o movimento de coloração da natureza se devem apenas ao surgimento do novo dia, de o sol raiar, todos esses acontecimentos concretos.

Numa leitura mais aprofundada, identificamos dois aspectos que compõem a utopia da qual tratamos e, portanto, confirmariam o movimento de transposição. Ambos os detalhes se encontram sob o saber do sujeito que fala, logo, próximo do conhecimento proporcionado pela história, e da coragem a ser assumida pelo interpelado. A utopia da qual tratamos, em consequência, é a mescla do devaneio e da revelação, e se sucede pelo desinteresse sobre aquilo que já não é útil ou se mostra prestes a volver, amparada, portanto, pela coragem e o saber, como ressalta Coelho (1984).

No campo dos estudos sobre a relação entre devaneio e espaço, poderíamos nos dedicar a uma leitura das canções apenas sob esse ponto de vista; contudo, o momento é de trazer um recorte da fenomenologia do devaneio. Aponta Bachelard (2008) para um caminho em que a casa, no caso aqui a comunidade — favela — , fornece imagens que emergem a partir desse espaço íntimo, embora se encontrem outras pessoas. Essas impressões nada mais são do que os resultados do sonhar acordado, do devanear.

O devaneio cósmico nos faz habitar um mundo; dá ao sonhador a impressão de um em casa num universo imaginado. $\mathrm{O}$ mundo imaginado dá-nos um em casa em expansão, o inverso do em casa do quarto. [...]. Ao sonhar o universo, estamos sempre partindo, habitamos algures - num algures sempre confortável. Para bem designar um mundo sonhado, é preciso marcálo por uma felicidade. (BACHELARD, 1996, p. 170, destaques do autor).

De modo que a madrugada é o tempo, inclusive o lugar, em que se situam os crentes nas transformações conduzidas pelo novo dia. Poderíamos considerá-la, ainda, como um depósito onde encontramos o ato de espera dos sujeitos. Em outras palavras, Bloch (2005) afirma ser essa prática o gesto principal daqueles que se propõem a alterar os caminhos trilhados anteriormente. Nesse sentido, a madrugada seria, para os que são retratados nos sambas, a aliada que os moveria em direção à esperança. Ao romper da aurora, obra de Francisco Moraes Alves (o Chico Viola), Ismael Silva e Lamartine de Azeredo Babo, ou simplesmente Lamartine Babo, continua a destacar a fronteira do presente e a do futuro.

É intrigante imaginarmos que esse limiar possa já ter sido transposto pelo eu-lírico em determinado momento de sua vida. Ao irrompermos sobre essa possibilidade, assentamo-nos naquilo que nos arremeda ser uma verdade incontestável: o Sol surgirá e pintará os diversos ambientes com cores vivificantes. A dúvida, quanto ao que podemos expectar com o amanhecer, desaparece tão logo haja a confirmação do dia que raiará. Curiosamente, pois, faz com que pensemos num sujeito que se situa no presente, na madrugada, mas que para ela voltou apenas para contar os sucessos que serão alcançados.

Ao romper da aurora

Aurora vem raiando, anunciando o nosso amor ôôô... 


\title{
das Letras
}

\author{
Desperta a cidade \\ o sol no céu flutua \\ ele é a mocidade \\ a saudade é a lua. \\ ôôô... \\ Aurora vem raiando, \\ anunciando o nosso amor \\ ôôô... \\ A felicidade promete \\ mas não vem \\ lá vem a saudade \\ saudade é "querer bem". \\ ôôô... \\ Quando chega o dia \\ desaparece a tristeza \\ Fica a alegria \\ pela própria natureza \\ ôôô... \\ Aurora vem raiando, \\ anunciando o nosso amor \\ ôôô... \\ (CHICO VIOLA; SILVA; BABO, 2017).
}

À luz dessas considerações, estreitamos laços com a ideia de que

O homem é alguém que ainda tem muito pela frente. No seu trabalho e através dele, ele é constantemente remodelado. Ele está constantemente à frente, topando com limites que já não são mais limites; tomando consciência deles, ele os ultrapassa. (BLOCH, 2005, p. 243).

O avanço sobre aquilo que se dá no presente, desconsiderando, portanto, os limites, faz com que as personagens retratadas nas letras acima sejam dotadas de uma "consciência utópica". Em outras palavras, inconscientemente se sobrepondo ao ainda não vivido, elas se deparam com certas particularidades que destoam do instante, do tempo autêntico, podendo ser o derradeiro ou o horizonte. Deparamo-nos com indivíduos supostamente capazes de desenharem os mistérios por trás do futuro, de modo que, a nosso ver, relacionam-se tão somente com

[...] uma tentativa de atravessar a escuridão bem próxima do instante que acabou de ser vivido [...] O ainda-não consciente comunica-se e interage com o que-ainda-não-veio-a-ser, mais especificamente com o que está surgindo na história e no mundo. (BLOCH, 2005, p. 23).

No veio das ponderações esperançosas quanto ao próspero, não poderíamos desconsiderar os aspectos que marcam, inclusive, as esperanças dos marginalizados, as quais dizem respeito às suas heranças. Não seria inadequado associarmos a visão romantizada sobre o que pode ser alcançado finda a escuridão, com o que decorre da nacionalização do gênero musical samba e dos olhares voltados às camadas suburbanas que o executam. Ou seja, assim como se deu com a cultura afro-brasileira - essa 
ultrapassando a fronteira —, os admiradores dela se colocam a almejar resultados parecidos para suas vidas, sobretudo a amorosa.

Esses passos seguem, portanto, os da

[...] cultura popular brasileira [que], entre os anos 10 e 30, atravessou o Atlântico várias vezes, sendo apropriada pelos franceses de inusitadas maneiras, num fenômeno típico de transculturação [...] gerou muitas redefinições de identidade para vários grupos sociais, tanto na Europa quanto no Brasil. (VIANNA, 1995, p. 104).

\section{CONSIDERAÇÕES FINAIS}

Ainda que assegurem pelas suas canções um porvir distante dos malditos tempos remotos, como se naquele já tivessem vivido, quando por um viés histórico observamos o possível futuro dos suburbanos, a crença sobre aquele começa a se dissipar. Esse olhar para as transformações pelas quais passaram torna ainda mais explícito que muitos dos compositores não eram conscientes do jogo político incrustrado no discurso de salvaguardar o que era cantado em meio às ruas, feiras e jornada profissional.

Ao atentarem contra a minoria detentora dos controles que regiam a sociedade à época, os que compunham a camada popular não se aproximavam do processo de redefinição e reconstrução do "[...] exotismo que tanto seduziu o olhar do francês.". Assim sendo, sucumbia a camada popular, aos estrangeiros, "à opinião de europeu” (VIANNA, 1995, p.105). Logo, a visão romantizada dos possíveis/necessários novos recomeços descritos nas composições analisadas, junta-se à que cerca o surgimento da principal personagem brasileira, fazendo com que a espera não se desenhe prática real ${ }^{10}$.

\section{REFERÊNCIAS}

BACHELARD, G. A poética do devaneio. Trad. Antônio de Pádua Danesi. São Paulo: Martins Fontes, 1988.

- A poética do espaço. Trad. Antônio da Costa Leal e Lídia do Valle Santos Leal. São Paulo: Martins Fontes, 2008.

BENCHIMOL, J. Pereira Passos: um Haussmann tropical. Rio de Janeiro: Biblioteca Carioca, 1992.

BENTES, I. Sertões e favelas no cinema brasileiro contemporâneo: estética e cosmética da fome. Alceu, Rio de Janeiro, v. 8, n.15, p. 242-255, jul./dez. 2007.

BLOCH, E. O princípio esperança. v.1. Trad. Nélio Schneider. EDUERJ: Contraponto. Rio de Janeiro, 2005.

\footnotetext{
${ }^{10}$ Visão de um sujeito que não ultrapassa os limites sociais impostos pelos gerenciadores financeiros e culturais das urbes. Segundo Matos (1982, p. 67), "Com o culto da malandragem, o mundo negro, pobre e marginal do samba chega à fronteira cultural de classes, e passa a transitar por ela, sem todavia cruzá-la de vez.".
} 
CACASO; MEDEIROS, E. Aurora de pa\% Disponível em: <https://www.letras.mus.br/elton-medeiros/1559636/>. Acesso em: 5 jun. 2017.

CALDAS, S; ORESTES, B. Chão de estrelas. Disponível em: <https://www.letras.mus.br/silvio-caldas/205192/>. Acesso em: 17 jun. 2017.

CARTOLA; CACHAÇA, C; CARVALHO, H. B de. Alvorada. Disponível em: <https://www.letras.mus.br/cartola/88700/>. Acesso em: 5 jun. 2017.

CHAUÍ, M. Notas sobre Utopia. In: SOUZA, Cidoval Morais de (Org.). Um convite à utopia [Livro eletrônico]. Campina Grande: EDUEPB, 2016. Disponível em: <wmw.uepb.edu.br/download/ ebooks/Um-Convite-a-Utopia.pdf>. Acesso em: 12 jun. 2017.

CHEVALIER, J.; GHEERBRANT, A. Dicionário de símbolos. Trad. Rio de Janeiro: J. Olympio, 1988.

CHICO VIOLA; SILVA, I; BABO, L. Ao romper da aurora. Disponível em: <https://www.letras.mus.br/ismael-silva/1629407/>. Acesso em: 5 jun. 2017.

COELHO, T. O que é utopia? 4. ed. São Paulo: Brasiliense, 1984

DANTAS, J. O canto e a canção: MPB. Rio de Janeiro: Ao Livro Técnico, 1988.

GALEANO, E. O tempo que virá. In: SOUZA, Cidoval Morais de (Org.). Um convite à utopia [Livro eletrônico]. Campina Grande: EDUEPB, 2016. Disponível em: <www.uepb.edu.br/download/ebooks/Um-Convite-a-Utopia.pdf>. Acesso em: 12 jun. 2017.

GALVÃO, W. N. Malandro e trabalhador. In: Canção e poder: itinerários. Disponível em: <http://www.teoriaedebate.org.br/materias/cultura/cancao-e-poder-itinerarios $>$.

Acesso em: 1 maio 2017.

BUARQUE, A. Minidicionário Aurélio da Lingua Portuguesa. Rio de Janeiro: Nova Fronteira, 1993.

MATOS, C. Acertei no milhar: malandragem e samba no tempo de Getúlio. Rio de Janeiro: Paz e Terra, 1982.

MAT'TUELLA, L. Por um resgate da transposição: o fragmento como elemento utópicointerpretativo em Ernst Bloch. In: SOUZA, Ricardo Timm; RODRIGUES, Ubiratane de Morais (Org.). Ernst Bloch: atualidade das utopias concretas. vol. 1. [recurso eletrônico]. Porto Alegre: Editora Fi, 2016. p. 155-177.

OLIVEIRA, M. M. Uma (re)leitura da história oficial. Revista de Letras. n.1, 1996.

ROMANELLI, F. Alvorada lá no morro, que beleza! Hermínio, a paisagem e as cores do samba. Em tese. Belo Horizonte. v. 21 n. 3 set./dez. 2015. p. 104-118.

TRIVIÑOS, A. N. S. Introdução à pesquisa em ciências sociais: a pesquisa qualitativa em educação. São Paulo: Atlas, 1987.

VIANNA, H. O mistério do samba. 3. ed. Rio de Janeiro: Jorge Zahar, 1995.

VIEIRA, A. Princípio Esperança e a "herança intacta do marxismo" em Ernst Bloch. Anais do $5^{\circ}$ Colóquio Internacional marxengels, 2007. Disponível em $<$ http://www.unicamp.br/cemarx/anais_v_coloquio_arquivos/arquivos/comunicacoes /gt1/sessao6/Antonio_Rufino.pdf >. Acesso em: 12 jun. 2017.

Recebido em: 05/06/2018

Aprovado em: 23/07/2018

Publicado em: 01/12/2018 